\title{
Update on differences between childhood-onset and adult-onset systemic lupus erythematosus
}

\author{
Rina Mina and Hermine I Brunner*
}

\begin{abstract}
Systemic lupus erythematosus (SLE) is a complex autoimmune disease and occurs worldwide in both children and adults. The estimated annual incidence among children is 2.22/100,000 and among adults is 23.2/100,000 in the United States. There is increasing understanding about differences in disease manifestations, medication use, and disease severity between those with childhood-onset SLE as compared with adult-onset SLE. Children have a more fulminant disease onset and course than adults with $S L E$, resulting in two to three times higher mortality. In future years, we anticipate more insight into the genetics between childhood-onset SLE and adultonset SLE to help delineate the best therapies for both subsets of patients.

Keywords: childhood-onset systemic lupus erythematosus, systemic lupus erythematosus, children, lupus, adults, adolescents
\end{abstract}

\section{Introduction}

Systemic lupus erythematosus (SLE) is a complex autoimmune disease that can affect all organ systems due to alterations of both the innate and adaptive immune systems. Although onset during infancy is rare, the incidence of SLE rises steadily during childhood until mid-adulthood, especially among females. This review appraises recent updates concerning the differences and similarities of SLE with onset in childhood (CSLE) as opposed to onset in adulthood (aSLE). Focus is placed on updates addressing nomenclature, epidemiology, lupus nephritis treatment, clinical and immunological manifestations, and pathogenesis as they have been published in the peer-reviewed medical literature since 2008.

*Correspondence: hermine.brunner@cchmc.org

Division of Rheumatology, Cincinnati Children's Hospital Medical Center, University of Cincinnati, 3333 Burnet Avenue, MC 4010, Cincinnati, OH 45229, USA

\section{Updates on classification and nomenclature}

Diagnostic criteria are used to establish the presence of disease clinically, while classification criteria are needed for research to define more homogeneous patient subgroups for diseases with heterogeneous phenotypes. Various classification criteria have been developed and validated in aSLE. Currently, the classification criteria set most widely used in children and adults with SLE is that of the American College of Rheumatology (ACR) updated in 1997 [1]. Concerns about lack of sensitivity in adequately capturing the diverse SLE phenotypes prompted the development of revised classification criteria for aSLE by the Systemic Lupus International Collaborating Clinics (Table 1) [2]. Initial validation studies suggest the Systemic Lupus International Collaborating Clinics classification criteria to be more sensitive than the 1997 ACR classification criteria (97\% vs. $83 \%, P<0.0001)$ but less specific $(84 \%$ vs. $96 \%, P<0.0001)$ [2].

Unfortunately, previous studies have failed to address the accuracy of the Systemic Lupus International Collaborating Clinics or the 1997 ACR classification criteria that have been developed for aSLE when used in pediatrics. Indeed, Ferraz and colleagues published the only peer-reviewed study that validated SLE classification criteria for cSLE, reporting 96\% sensitivity and 100\% specificity of the 1982 American Rheumatism Association classification criteria, based on data from 103 children with cSLE and 101 children with other rheumatic diseases from Brazil [3].

In contrast to juvenile idiopathic arthritis and various other forms of autoimmune-mediated arthritis, including rheumatoid arthritis, there is no universally accepted maximum age up to which cSLE rather than aSLE is diagnosed. A recent systematic review by Silva and colleagues reports that previously published research used various age thresholds when referring to cSLE, ranging from 14 to 20 years. This variation probably impacted on past epidemiological estimates and diminished the comparability of earlier cSLE studies [4]. The authors suggest an upper age limit for the diagnosis of cSLE at 18 years based on the published literature and issues pertaining to the provision of medical care. The 
Table 1. Systemic Lupus International Collaborating Clinics classification criteria for systemic lupus erythematosus

\begin{tabular}{|c|c|}
\hline Clinical criteria & Immunological criteria \\
\hline \multirow{2}{*}{$\begin{array}{l}\text { 1. Acute cutaneous lupus: including lupus malar rash, bullous lupus, } \\
\text { toxic epidermal necrolysis variant of SLE, maculopapular lupus rash, } \\
\text { photosensitive lupus rash in the absence of dermatomyositis, or subacute } \\
\text { cutaneous lupus }\end{array}$} & 1. Antinuclear antibody above laboratory reference range \\
\hline & $\begin{array}{l}\text { 2. Anti-dsDNA antibody above laboratory reference range, except ELISA: twice } \\
\text { above laboratory reference range }\end{array}$ \\
\hline \multirow{2}{*}{$\begin{array}{l}\text { 2. Chronic cutaneous lupus: including classical discoid rash, localized or } \\
\text { generalized, hypertrophic lupus, lupus panniculitis, mucosal lupus, lupus } \\
\text { erythematosus tumidus, chillblain lupus, discoid lupus/lichen planus overlap }\end{array}$} & 3. Anti-Smith antibody \\
\hline & \multirow{2}{*}{$\begin{array}{l}\text { 4. Anti-phospholipid antibody: any of the following lupus anticoagulant, false- } \\
\text { positive RPR, medium or high titer anticardiolipin (lgA, } \lg G \text { or } \lg M) \text {, anti- } \beta_{2}^{-} \\
\text {glycoprotein I (IgA, IgG or lgM) }\end{array}$} \\
\hline \multirow{2}{*}{$\begin{array}{l}\text { 3. Oral ulcers: palate, buccal, tongue, or nasal ulcers, in the absence of other } \\
\text { causes }\end{array}$} & \\
\hline & 5. Low complement, low C3, low C4, low $\mathrm{CH} 50$ \\
\hline $\begin{array}{l}\text { 4. Nonscarring alopecia (diffuse thinning or hair fragility with visible broken } \\
\text { hairs) in the absence of other causes }\end{array}$ & 6. Direct Coombs test in the absence of hemolytic anemia \\
\hline \multirow{2}{*}{$\begin{array}{l}\text { 5. Synovitis involving two or more joints, characterized by swelling or } \\
\text { effusion or tenderness in two or more joints and } 30 \text { minutes or more of } \\
\text { morning stiffness }\end{array}$} & SLICC criteria for SLE classification require: \\
\hline & \multirow{4}{*}{$\begin{array}{l}\text { 1. Fulfillment of at least four criteria, with at least one clinical criterion and one } \\
\text { immunologic criterion } \\
\text { or } \\
\text { 2. Lupus nephritis as the sole clinical criterion in the presence of antinuclear } \\
\text { antibody or anti-dsDNA antibodies }\end{array}$} \\
\hline \multirow{2}{*}{$\begin{array}{l}\text { 6. Serositis: typical pleurisy for more than } 1 \text { day, or pleural effusions, or pleural } \\
\text { rub, typical pericardial pain for more than } 1 \text { day, or pericardial effusion or } \\
\text { pericardial rub, or pericarditis by ECG, in the absence of other causes }\end{array}$} & \\
\hline & \\
\hline $\begin{array}{l}\text { 7. Renal: urine protein/creatinine (or } 24 \text {-hour urine protein) representing } \\
500 \mathrm{mg} \text { protein/24 hours, red blood cell casts }\end{array}$ & \\
\hline \multicolumn{2}{|l|}{$\begin{array}{l}\text { 8. Neurologic: seizures, psychosis, mononeuritis multiplex, myelitis, } \\
\text { peripheral or cranial neuropathy, acute confusional state, in the absence of } \\
\text { other causes }\end{array}$} \\
\hline \multicolumn{2}{|l|}{ 9. Hemolytic anemia } \\
\hline \multicolumn{2}{|l|}{$\begin{array}{l}\text { 10. Leukopenia }\left(<4,000 / \mathrm{mm}^{3} \text { at least once) in the absence of other known }\right. \\
\text { causes or lymphopenia }\left(<1,000 / \mathrm{mm}^{3} \text { at least once) in the absence of other }\right. \\
\text { known causes }\end{array}$} \\
\hline $\begin{array}{l}\text { 11. Thrombocytopenia }\left(<100,000 / \mathrm{mm}^{3}\right) \text { at least once in the absence of other } \\
\text { known causes }\end{array}$ & \\
\hline
\end{tabular}

ECG, eletrocardiogram; SLE, systemic lupus erythematosus; SLICC, Systemic Lupus International Collaborating Clinics. Adapted from [2].

same review attempts to achieve more uniformity in terminology when referring to children and adolescents with onset of SLE prior to adulthood [4].

\section{Recent epidemiologic estimates of adult-onset SLE and childhood-onset SLE}

The female to male ratio increases from 4:3 for cSLE to 9:1 during the reproductive years. SLE is also more common among non-White populations. Changes in the ethnic and racial composition of some countries, such as the United States, Canada, and several European countries, may partly explain the rising incidence and prevalence of SLE in some geographic regions. The importance of sociodemographic factors and changed environmental factors for the development of SLE is supported by the highest SLE prevalence in the South of the United States and in high-poverty areas $[5,6]$.

MEDICAID is the US health program for individuals and families with limited monetary incomes and resources [7]. Recent analyses of the US administrative MEDICAID database suggest that aSLE is about 10 times more common than cSLE; $84 \%$ of cSLE patients are female, $40 \%$ of them are African American and 25\% are
Hispanic [6]. Among the 23.9 million MEDICAID enrollees aged 18 to 65 years, the annual incidence and prevalence of aSLE is 23.2 and 143.7 cases per 100,000 enrollees, respectively, with a female to male ratio of $6: 1$. Likewise, the annual incidence of cSLE is $2.22(95 \%$ confidence interval $(\mathrm{CI})=2.05$ to 2.40 ) per 100,000 children and its prevalence is $9.73(95 \% \mathrm{CI}=9.38$ to $10.08)$ per 100,000 children between the ages of 3 and 18 years enrolled in MEDICAID. With respect to lupus nephritis, the annual incidence and prevalence rates of lupus nephritis are $0.72(95 \% \mathrm{CI}=0.63$ to 0.83$)$ and 3.64 ( $95 \% \mathrm{CI}=3.43$ to 3.86 ) per 100,000 children for the over 30 million children covered by MEDICAID [8]. This compares with annual incidence and prevalence rates of lupus nephritis at 6.9 and 30.9 per 100,000 adults [5]. MEDICAID data confirmed non-White race and female gender to be risk factors for developing lupus nephritis in both cSLE and aSLE $[5,8]$.

One must note that especially the adult MEDICAID population does not provide a good representation of the overall US population, and that patients with end-stage renal disease are generally covered by other state programs than MEDICAID. 


\section{Updates on pathogenesis}

The pathogenesis of SLE remains a vibrant area of research [8]. Early onset of SLE features is associated with an increased number of known SLE-susceptibility risk alleles, which may partly explain the increased severity of cSLE compared with aSLE [9]. Type 1 interferons are thought to be associated with the increased incidence of SLE in early adulthood. Indeed, about one-half of genetic variants associated with SLE to date can be linked to type 1 interferon production or signaling. Serum IFN $\alpha$ activity was found to be higher among younger and affected individuals in SLE family cohorts [10]. Interestingly, known genetic risk factors contribute to the risk of developing SLE by an average of $48 \%$ in Gullah and $25 \%$ in African-Americans, but not importantly among Hispanic and European-American individuals [9].

There is increasing evidence that miRNAs are involved in the differential expression of SLE-associated genes $[11,12]$. These noncoding RNAs may be useful organspecific SLE biomarkers [13]. Several miRNAs - such as miR-146a, a negative regulator of the type I interferon pathway, miR-21, miR-148a, and miR-125a - are differentially expressed in SLE, and the concentrations of some miRNAs are associated with SLE activity.

Targeted assessment of $\sim 1,000$ genes ( 10,000 SNPs) that are part of candidate pathways of SLE was performed in 253 trios of parents and children with cSLE (753 subjects). This assessment led to the identification of two novel SLE-associated genes, namely SELP (P-selectin gene) and IRAK1 (interleukin-1 receptor-associated kinase 1 gene) [14]. Another large multi-ethnic cohort study of 5,317 controls, 5,337 aSLE cases and 769 cSLE cases yielded confirmation of two SLE risk genes: PTPN22 (protein tyrosine phosphatase nonreceptor 22 gene) and IRF5 (interferon regulatory factor 5 gene) [15]. Furthermore, five novel SLE risk loci were described: KLRG1 (killer cell lectin-like receptor G1), IL-16, PTPRT (tyrosine-protein phosphatase T), TLR8 (toll-like receptor 8 ) and caspase 10 [15].

Further research is needed to delineate the biological effects caused by such genetic variations and establish their importance for the noted phenotypic differences between cSLE and aSLE.

\section{Updates on differences in the clinical presentation and course}

Remission is uncommon with aSLE and exceedingly rare with cSLE in North America [16]. There are reports from Canada suggesting a higher frequency of neurological and renal involvement at the time of diagnosis among children as compared with adults with SLE $[17,18]$. The histological classes of lupus nephritis are similarly distributed in cSLE and aSLE [19]. A study evaluating patient data from 28 cSLE cases, 107 aSLE cases and
14 late-onset SLE cases (that is, onset at age $<16$ years, 16 to 50 years and $\geq 50$ years, respectively) found age to be unrelated to kidney damage after adjustment for baseline renal parameters, duration of lupus nephritis, use of cyclophosphamide, and initial treatment response [20]. A study comparing the histopathology and course of lupus nephritis in patients age $\leq 18$ years $(n=23)$ and those of age $\geq 50$ years $(n=13)$ reports crescents on biopsy to be more common in the cSLE group than in the late-onset group ( $74 \%$ vs. $30 \%, P=0.02$ ), but there are no statistically significant differences in the activity or interstitial fibrosis on biopsy, or in clinical kidney parameters including hypertension and estimated glomerular filtration rate at presentation. However, there appear to be differences in response to therapy because, after 12 months of treatment, three of the cSLE patients but none of the lateonset patients progressed to dialysis [21].

Despite the suggested relevance of hormonal factors for the pathoetiology of SLE, a matched cohort study comparing prepubertal with pubertal cSLE demonstrated no important differences in disease features between groups; irrespective of pubertal status, the most commonly encountered cSLE features at the time of diagnosis were malar rash, arthritis, hematologic abnormalities, and lupus nephritis [22]. Further investigations are needed to study the effects of the hormonal changes that occur during puberty in relations to the mechanisms leading to overt cSLE.

Several studies from Europe and Latin America directly compared disease features and laboratory abnormalities with cSLE and aSLE [23-25]. The relationship between the age at onset and phenotypes of SLE was explored in a multi-racial cohort study of 1,317 cSLE and aSLE patients. Compared with aSLE, disease onset during childhood carried a higher risk of developing lupus nephritis, malar rash, anti-dsDNA antibody positivity, and hemolytic anemia (odds ratio $(\mathrm{OR})=3.03,2.13,2.08$, and 2.50, respectively; all Bonferroni corrected $P<0.004$ ) [9]. Additionally, patients with aSLE have less active disease over time than those with cSLE - that is, lower time-adjusted mean SLE Disease Activity Index scores (4.6 vs. 5.7, $P=0.012$ ) [18] - with differences largely accounted for due to renal and central nervous system involvement [17]. The abovementioned observations are in line with those of a recent meta-analysis of a total of 905 cSLE patients and 5,993 aSLE patients [26], which confirmed higher average disease activity at diagnosis in cSLE than aSLE (mean (95\% CI) difference in SLE Disease Activity Index scores $=4.73(2.13$ to 7.32$)$ ). As per this metaanalysis fever, thrombocytopenia, mucocutaneous involvement, urinary casts, seizures, and hemolytic anemia are all more commonly encountered in cSLE than aSLE, with ORs ranging from 1.3 to 2.4. Conversely, 
Sicca syndrome and pleuritis are both about twice more common in aSLE than in cSLE (Table 2) [26].

While virtually all patients with SLE test positive for circulating antinuclear antibodies, cSLE and aSLE cohorts also feature similar frequencies for anti-Smith, anti-RNP, anti-Ro/SSA, and anti-La/SSB antibodies $[24,25]$. However, based on meta-analysis, the frequency of some other immunological abnormalities is associated with the age at diagnosis. Anticardiolipin IgG/IgM antibody positivity appears to be significantly more common among cSLE patients than aSLE patients $(\mathrm{OR}=1.66$; $95 \%$ $\mathrm{CI}=1.20$ to 2.28). Because of their high frequency of infectious processes, transient and nonpathogenic anticardiolipin antibody positivity may occur more commonly in children. In general, antiphospholipid antibody-related thrombosis is rare in children, and prothrombotic or vasculopathic factors that are frequent in adults are uncommon in children. Rheumatoid factor positivity is more frequently encountered when SLE starts in adulthood as opposed to earlier in life ( $\mathrm{OR}=0.53$; 95\% $\mathrm{CI}=0.32$ to 0.87 ) (Table 2) [27]. Both of the abovementioned meta-analyses are limited by discrepancies in the threshold age used to define cSLE and the heterogeneity of the data considered [26,27].

Neuropsychiatric involvement with SLE is at least as common in children as it is in adults, with the former experiencing symptoms especially within 1 year post diagnosis with SLE (70\% vs. 28\%) [28,29]. The Grupo Latino Americano de Estudio del Lupus cohort reports a significantly higher prevalence of pseudotumor cerebri, transient ischemic attack, and seizures in CSLE when directly compared with aSLE [25]. Psychosis, chorea, and any type of encephalopathy occur with cSLE preferentially, while cranial nerve abnormalities are more frequent in aSLE. Depression is the most common mood disorder in SLE patients of all ages, without apparent differences in prevalence across age strata. Neurocognitive impairment seems similarly common among children and adults with SLE [17] but reported frequencies vary depending on the chosen categorization scheme $[30,31]$. A recent review further outlined differences and similarities in CSLE and aSLE with respect to neuropsychiatric involvement [32].

The prevalence of osteopenia and osteoporosis is similar among CSLE and premenopausal aSLE patients. Poor bone health is much more common among postmenopausal aSLE patients, probably reflecting the effects of traditional osteoporosis risk factors [33,34]. In children, the prescribed dose of steroids is negatively associated with bone formation as measured by serum osteocalcin (Spearman rank correlation coefficient $r=-0.34, P<0.0001$ ) [35]. Compared with the general population, hypovitaminosis $\mathrm{D}$ is more prevalent among children and adults with SLE. There remains conflicting evidence as to whether high SLE disease activity and/or proteinuria increases the risk of vitamin D deficiency and vice versa [35-38].

\section{Longer-term morbidity}

A 2011 meta-analysis found no significant differences in the average SLE damage index scores between CSLE and aSLE [26]. It is noteworthy that the SLE damage index includes several items that are more common among older populations in general but no items of health concerns that are specific to children, including but not limited to growth and physical maturation. Future studies directly comparing cSLE and aSLE for risk factors of early versus late disease damage are needed.

While rare during childhood, clinically recognizable coronary artery disease is reported in 6 to $9 \%$ of adults with SLE. Ischemic heart disease remains an important cause of morbidity and mortality in aSLE. A 3-year randomized, double-blind, placebo-controlled clinical trial of atorvastatin in CSLE suggests male gender $(P<0.001)$, higher body mass index $(P<0.001)$, decreased creatinine clearance $(P=0.031)$, older age $(P<0.001)$, and azathioprine use $(P=0.005$ to 0.0102$)$ all to be positively associated with an increased burden of subclinical coronary artery disease as measured by carotid intima-media thickening [39]. Notably, moderate prednisone doses $(0.15$ to $0.4 \mathrm{mg} / \mathrm{kg} /$ day $)$ were associated with fewer abnormal carotid intima-media thickening measurements $(P=0.024)$, and there was a trend towards slowed progression of subclinical atherosclerosis over time [40].

Five-year renal survival rates in cSLE patients with proliferative lupus nephritis are at 85 to $91 \%$, comparable with those reported from some aSLE cohorts [41]. Lupus nephritis accounts for $1.9 \%$ of kidney transplants among adults and 3\% among children, according to the US Renal Data System [42]. The poor prognosis of children with cSLE and end-stage renal disease is troublesome. There is a $22 \%$ mortality rate during the 5 -year period since the initiation of renal replacement therapy, with cardiopulmonary compromise and infections accounting for $47 \%$ of all causes of death [43]. Long-term outcomes beyond 5 to 10 years are lacking, emphasizing the need for further research in long-term renal outcomes of children with cSLE. Based on the North American Renal Transplant Cooperative Study Database, cSLE and aSLE kidney graft survival is similar to that for patients with other adult or pediatric diseases, for both living and cadaveric kidney donors [41].

\section{Mortality}

There are encouraging reports from developed countries of 5-year survival rates that exceed $90 \%$ among both children and adults with SLE, $86 \%$ at 10 years, and $79 \%$ at 
Table 2. Comparison of clinical manifestations in childhood-onset SLE and adult-onset SLE

\begin{tabular}{|c|c|c|c|}
\hline Clinical manifestations & Odds ratio & $95 \%$ confidence interval & $r^{2}(\%)^{\mathrm{a}}$ \\
\hline \multicolumn{4}{|c|}{ More common in childhood-onset SLE } \\
\hline Fever & 1.48 & 1.24 to 1.76 & 0 \\
\hline Thrombocytopenia & 1.30 & 1.10 to 1.55 & 0 \\
\hline Ulcers/mucocutaneous & 1.35 & 1.13 to 1.61 & 0 \\
\hline Urinary cellular casts & 2.35 & 1.68 to 3.29 & 0 \\
\hline Seizures & 2.32 & 1.65 to 3.25 & 16 \\
\hline Hemolytic anemia & 1.90 & 1.44 to 2.52 & 17 \\
\hline Combined $\lg \mathrm{G}$ and $\lg \mathrm{M} \mathrm{aCL}$ & 1.66 & 1.20 to 2.28 & 41 \\
\hline \multicolumn{4}{|l|}{ More common in adult-onset SLE } \\
\hline Sicca & 0.42 & 0.27 to 0.64 & 0 \\
\hline Pleuritis & 0.69 & 0.54 to 0.88 & 0 \\
\hline Rheumatoid factor & 0.53 & 0.32 to 0.87 & 0 \\
\hline
\end{tabular}

$\mathrm{aCL}$, anti-cardiolipin antibody; SLE, systemic lupus erythematosus. ${ }^{2}$ statistic was used to examine the between-study heterogeneity. Only disease features with $R^{2}<50 \%$ were included in the table.

15 years $[44,45]$. However, the prognosis of SLE reported from developing countries remains less favorable. A cohort study from Thailand suggests survival rates of only $76 \%$ at 5 years and $64 \%$ at 10 years after diagnosis with cSLE [46].

Higher disease activity is associated with higher disease damage and mortality in both cSLE and aSLE $[47,48]$. cSLE continues to carry a higher mortality risk than aSLE [27]. Compared with aSLE, patients with cSLE enrolled in the LUMINA cohort had a twofold higher mortality risk [49] and those in the University of California Lupus Outcomes Study had a more than three times higher risk of dying (hazard ratio $=3.1,95 \% \mathrm{CI}=1.3$ to 7.3 ) [50]. Corrected for age, disease duration, and other patient characteristics [50], low socioeconomic status (hazard ratio $=1.9,95 \% \mathrm{CI}=1.1$ to 3.2 ) and the presence of endstage renal disease (hazard ratio $=2.1,95 \% \mathrm{CI}=1.1$ to 4.0) were found to be important risk factors of SLEassociated mortality.

\section{Updates on surrogate and biological measures}

The SLE Responder Index has been developed to capture improvement of aSLE in the clinical trials of belimumab. When used in children and adolescents, the SLE Responder Index has high specificity but only modest sensitivity in capturing cSLE improvement as rated by the treating physician or patient (parent) [51]. International consensus formation efforts resulted in several key criteria for clinical remission and inactive disease in cSLE [52] (Table 3). Similarly, criteria for global flares have been developed for cSLE and aSLE [53,54]. The recently published consensus treatment plans for lupus nephritis in cSLE utilized renal response definitions adapted from those proposed by the ACR for proliferative and membranous renal disease in $\operatorname{aSLE}[55,56]$.
There is active research in improved SLE biomarkers. Several novel lupus nephritis biomarkers appear useful for the early diagnosis of lupus nephritis and suited for anticipating renal flares [57-59]. Among these urinary biomarkers, neutrophil gelatinase-associated lipocalin and monocyte chemoattractant protein 1 will most probably be first available to clinicians over the upcoming years. Select cell-bound complement activation products have been associated with extra-renal flares in cSLE and aSLE, with confirmation from longitudinal studies being awaited [60]. The interested reader is directed towards a recent review of lupus nephritis biomarkers [61].

\section{Updates on differences in management strategies}

There has been an increased focus on the development of quality indicators; that is, measures of the quality of medical care delivered to individuals with SLE [2]. Two sets of quality indicators for aSLE are available, and international consensus yielded cSLE quality indicators recently [62-64]. Quality indicators can be used to help define minimum treatment standards of medical care for cSLE and aSLE. About one-third of the quality indicators for cSLE are identical to those for aSLE, while the remaining quality indicators for children are somewhat more conservative in terms of recommending closer monitoring than that deemed necessary for aSLE.

Steroids are more commonly used for the treatment of cSLE than aSLE $[16,18]$, probably to address differences in disease phenotypes. Furthermore, a retrospective cohort study of cSLE patients treated between 1988 and 2008 reports that the early-onset group (age $<12$ years) requires significantly higher daily steroid doses than children diagnosed with cSLE during adolescence $(0.6 \mathrm{mg} / \mathrm{kg}$ prednisone-equivalent vs. $0.2 \mathrm{mg} / \mathrm{kg}$ prednisoneequivalent, $P<0.05)[22]$. 


\begin{tabular}{|c|c|c|c|c|c|}
\hline \multirow[b]{2}{*}{ Construct } & \multirow[b]{2}{*}{$\begin{array}{l}\text { Minimal time } \\
\text { interval }\end{array}$} & \multicolumn{4}{|c|}{ Medication usage } \\
\hline & & Corticosteroids & Immunosuppressives & $\begin{array}{l}\text { Preventive } \\
\text { medications } s^{\mathrm{a}}\end{array}$ & $\begin{array}{l}\text { Medications to } \\
\text { treat damage }\end{array}$ \\
\hline Inactive disease $\mathrm{b}^{\mathrm{b}}$ & Yes & Permissible & Permissible & Permissible & Permissible \\
\hline $\begin{array}{l}\text { Clinical remission on } \\
\text { medication }\end{array}$ & 6 months & Permissible & Permissible & Permissible & Permissible \\
\hline $\begin{array}{l}\text { Clinical remission on } \\
\text { preventive medication }\end{array}$ & 6 months & No & No & Permissible & Permissible \\
\hline $\begin{array}{l}\text { Clinical remission off } \\
\text { medication }\end{array}$ & 12 months & No & No & No & Permissible \\
\hline
\end{tabular}

aPreventive medications include systemic medications that can be used to prevent disease damage, such as statins, aspirin, angiotensin-converting enzyme inhibitors, angiotensin receptor blockers, bisphosphonates, vitamin D, and omega-3 fatty acids. ${ }^{b}$ Medication exposure is not considered.

The same armamentarium of immunosuppressive drugs is used for cSLE and aSLE. Overall, nonbiologic disease-modifiying medications are prescribed more frequently to children than adults with SLE [16-18], but methotrexate is more commonly used for aSLE (31\% vs. 9\%) [18] and intravenous cyclophosphamide for cSLE therapy [49]. In 2012 belimumab (anti-BLyS/BAFF) was approved by health-regulatory agencies for the treatment of active, autoantibody-positive aSLE despite use of standard therapy $[65,66]$. Added to background therapy, clinical trials showed that significantly more patients improve with belimumab compared with placebo, especially with respect to mucocutaneous and musculoskeletal SLE involvement and immunological abnormalities. A clinical trial aimed at assessing the safety and pharmacokinetics of belimumab in CSLE is ongoing (NCT01649765), with results expected in 2016.

Based on case reports and anecdotal experience, antiCD20 blockade leads to improvement of hematologic abnormalities, neuropsychiatric SLE, anti-phospholipidmediated pathology, and lupus nephritis of SLE patients of all ages $[67,68]$. However, a randomized, double-blind, placebo-controlled trial failed to document a benefit of rituximab over placebo for the control of aSLE activity [69]. There is an ongoing clinical trial of rituximab in cSLE (results expected in 2015) and several clinical trials of rituximab in aSLE, mainly assessing rituximab benefits for the treatment of select disease features or as part of combination therapy.

To promote evidence-based treatments in SLE, standardized therapy regimens have been developed for children and adults with lupus nephritis [55,70,71]. The delineation of uniform steroid regimens for children with proliferative lupus nephritis must be considered a major achievement [55]. Notably, lower steroid doses are recommended for adults as compared with children with lupus nephritis [16-18].

Mycophenolate mofetil and cyclophosphamide are deemed cornerstones of lupus nephritis therapy. A subanalysis of a total of only 25 children with lupus nephritis who were enrolled in a large randomized clinical trial of mycophenolate mofetil (target dose $3.0 \mathrm{~g} /$ day) versus cyclophosphamide ( 0.5 to $\left.1.0 \mathrm{~g} / \mathrm{m}^{2} / \mathrm{month}\right)$ [72] showed a trend towards better renal response to 24-week induction therapy with mycophenolate mofetil than with cyclophosphamide (7/10 (70\%) vs. 8/15 (53\%)) [73]. Although this subanalysis is vastly underpowered, the trend is in line with the results of larger trial published in 2005 [72]. Likewise, both the cSLE subanalysis and the main trial report more effective maintenance of renal remission with mycophenolate mofetil as compared with azathioprine, although this difference was not statistically significant in the cSLE subanalysis $(7 / 8(87.5 \%)$ vs. $3 / 8$ (37.5\%), $P=$ not significant)] [73,74]. The EuroLupus trial enrolled patients as young as 14 years old; however, there are no published subanalyses regarding the efficacy of the EuroLupus regimen specific for cSLE or the number of patients with cSLE enrolled in this study. The interested reader is referred to a 2012 Cochrane review of the treatment of lupus nephritis, which, unfortunately, does not consider information from children with lupus nephritis [75].

\section{Cost of care}

Based on a systematic review, the annual direct medical cost of aSLE in the United States ranges from $\$ 13,735$ to $\$ 20,926$, with medications, hospitalization, and outpatient care accounting for 19 to $30 \%, 16$ to $50 \%$, and 24 to $56 \%$ of the overall cost, respectively [76].

Higher direct costs were accrued by patients with lupus nephritis compared with those without kidney disease (range: $\$ 29,034$ to 62,651 vs. $\$ 12,273$ to 16,575 ). These estimates, which were derived from medical claim data and self-reported resource utilization, are in line with a recent analysis of the US Healthcare Cost and Utilization Project KIDs Inpatient Database. The presence of lupus nephritis was identified to be a key determinant for higher hospitalization charges; these, on average, for children with lupus nephritis were $\$ 43,100$ as compared 
with only $\$ 28,500$ for cSLE patients without kidney disease $(P<0.0001)$ [77]. To date, there is only one study that directly compares the cost of medical care of cSLE with that of aSLE [16]. Herein, the care of a child is roughly $300 \%$ that of an adult with SLE.

Estimates of the mean annual indirect costs with aSLE in the United States are $\$ 1,093$ to 14,614 , while employment rates range from 35.8 to $55 \%$, and average durations of annual short-term sick leave are between 7.0 and 64.8 days [78]. Indirect costs incurred with cSLE have not been studied in detail, but one must consider anticipated loss of productivity upon entry into the workforce and reduction of productivity of family members currently involved in the care of the child with cSLE. Whether there are differences in indirect costs and disability rates between cSLE and aSLE remains to be seen.

\section{Conclusions}

aSLE is about 10 times more common than cSLE in the United States but children with cSLE have a more severe disease than their adult counterparts. Lupus nephritis has a profound negative impact on survival and results in high healthcare expenditure of both children and adults. During the preceding 5 years, there has been a move towards defining differences between CSLE and aSLE on a biological level but clear explanations are still lacking. Standardization of lupus nephritis treatments of children and adults with SLE has occurred, and measures of quality of medical care have been defined. One hopes that this will result in improved health outcomes with cSLE and aSLE. Nonetheless, there remains a dire need for more efficacious and less toxic therapies. In this millennium only belimumab has been newly approved for the treatment of aSLE, while not a single drug has ever obtained an indication for cSLE. Benefitting from the findings of basic and translations research as well as improved measures of drug effectiveness, several medications are now in the drug development pipeline and are expected to help improve the prognosis of children and adults with SLE.

This article is part of the series on Childhood rheumatic diseases, edited by Patricia Woo. Other articles in this series can be found at http://arthritis-research.com/series/childhood

\section{Abbreviations}

ACR, American College of Rheumatology; aSLE, adult-onset systemic lupus erythematosus; $\mathrm{Cl}$, confidence interval; $C S L E$, childhood-onset systemic lupus erythematosus; dsDNA, double-stranded DNA; ELISA, enzyme-linked immunosorbent assay; IFN, interferon; IL, interleukin; miRNA, microRNA; OR, odds ratio; SLE, systemic lupus erythematosus; SNP, single nucleotide polymorphism.

\section{Competing interests}

The authors declare that they have no competing interests.

Published: 21 August 2013
References

1. Hochberg MC: Updating the American College of Rheumatology revised criteria for the classification of systemic lupus erythematosus. Arthritis Rheum 1997, 40:1725.

2. Petri M, Orbai AM, Alarcon GS, Gordon C, Merrill JT, Fortin PR, Bruce IN, Isenberg D, Wallace DJ, Nived O, Sturfelt G, Ramsey-Goldman R, Bae SC, Hanly JG, Sanchez-Guerrero J, Clarke A, Aranow C, Manzi S, Urowitz M, Gladman D, Kalunian K, Costner M, Werth VP, Zoma A, Bernatsky S, Ruiz-Irastorza G, Khamashta MA, Jacobsen S, Buyon JP, Maddison P, et al: Derivation and validation of the Systemic Lupus International Collaborating Clinics classification criteria for systemic lupus erythematosus. Arthritis Rheum 2012, 64:2677-2686.

3. Ferraz MB, Goldenberg J, Hilario MO, Bastos WA, Oliveira SK, Azevedo EC, di Napoli D: Evaluation of the 1982 ARA lupus criteria data set in pediatric patients. Committees of Pediatric Rheumatology of the Brazilian Society of Pediatrics and the Brazilian Society of Rheumatology. Clin Exp Rheumatol 1994, 12:83-87.

4. Silva CA, Avcin T, Brunner HI: Taxonomy for systemic lupus erythematosus with onset before adulthood. Arthritis Care Res (Hoboken) 2012, 64:1787-1793.

5. Tiffin N, Adeyemo A, Okpechi I: A diverse array of genetic factors contribute to the pathogenesis of systemic lupus erythematosus. Orphanet J Rare Dis 2013, 8:2.

6. Feldman $\mathrm{CH}$, Hiraki LT, Liu J, Fischer MA, Solomon DH, Alarcon GS, Winkelmayer WC, Costenbader KH: Epidemiology and sociodemographics of systemic lupus erythematosus and lupus nephritis among U.S. adults with medicaid coverage, 2000-2004. Arthritis Rheum 2013, 65:753-763.

7. MEDICAID [http://medicaid.gov]

8. Tsokos GC: Systemic lupus erythematosus. N Engl J Med 2011, 365:2110-2121.

9. Webb R, Kelly JA, Somers EC, Hughes T, Kaufman KM, Sanchez E, Nath SK, Bruner G, Alarcon-Riquelme ME, Gilkeson GS, Kamen DL, Richardson BC, Harley JB, Sawalha AH: Early disease onset is predicted by a higher genetic risk for lupus and is associated with a more severe phenotype in lupus patients. Ann Rheum Dis 2010, 70:151-156.

10. Niewold TB, Adler JE, Glenn SB, Lehman TJ, Harley JB, Crow MK: Age- and sex-related patterns of serum interferon-alpha activity in lupus families. Arthritis Rheum 2008, 58:2113-2119.

11. Lashine YA, Seoudi AM, Salah S, Abdelaziz Al: Expression signature of microRNA-181-a reveals its crucial role in the pathogenesis of paediatric systemic lupus erythematosus. Clin Exp Rheumatol 2011, 29:351-357.

12. Tang Y, Luo X, Cui H, Ni X, Yuan M, Guo Y, Huang X, Zhou H, de Vries N, Tak PP, Chen S, Shen N: MicroRNA-146A contributes to abnormal activation of the type I interferon pathway in human lupus by targeting the key signaling proteins. Arthritis Rheum 2009, 60:1065-1075.

13. Lu J, Kwan BC, Lai FM, Tam LS, Li EK, Chow KM, Wang G, Li PK, Szeto CC: Glomerular and tubulointerstitial miR-638, miR-198 and miR-146a expression in lupus nephritis. Nephrology 2012, 17:346-351.

14. Jacob CO, Reiff A, Armstrong DL, Myones BL, Silverman E, Klein-Gitelman M, McCurdy D, Wagner-Weiner L, Nocton JJ, Solomon A, Zidovetzki R: Identification of novel susceptibility genes in childhood-onset systemic lupus erythematosus using a uniquely designed candidate gene pathway platform. Arthritis Rheum 2007, 56:4164-4173.

15. Armstrong DL, Reiff A, Myones BL, Quismorio FP, Jr., Klein-Gitelman M, McCurdy D, Wagner-Weiner L, Silverman E, Ojwang JO, Kaufman KM, Kelly JA, Merrill JT, Harley JB, Bae SC, Vyse TJ, Gilkeson GS, Gaffney PM, Moser KL, Putterman C, Edberg JC, Brown EE, Ziegler J, Langefeld CD, Zidovetzki R, Jacob CO: Identification of new SLE-associated genes with a two-step Bayesian study design. Genes Immun 2009, 10:446-456.

16. Hersh $A O$, von Scheven E, Yazdany J, Panopalis P, Trupin L, Julian L, Katz $P$, Criswell LA, Yelin E: Differences in long-term disease activity and treatment of adult patients with childhood- and adult-onset systemic lupus erythematosus. Arthritis Rheum 2009, 61:13-20.

17. Hiraki LT, Benseler SM, Tyrrell PN, Hebert D, Harvey E, Silverman ED: Clinical and laboratory characteristics and long-term outcome of pediatric systemic lupus erythematosus: a longitudinal study. J Pediatr 2008, 152:550-556.

18. Brunner HI, Gladman DD, Ibanez D, Urowitz MD, Silverman ED: Difference in disease features between childhood-onset and adult-onset systemic lupus erythematosus. Arthritis Rheum 2008, 58:556-562.

19. Zappitelli M, Duffy CM, Bernard C, Gupta IR: Evaluation of activity, chronicity 
and tubulointerstitial indices for childhood lupus nephritis. Pediatr Nephrol 2008, 23:83-91.

20. Mak A, Mok CC, Chu WP, To CH, Wong SN, Au TC: Renal damage in systemic lupus erythematosus: a comparative analysis of different age groups. Lupus 2007, 16:28-34.

21. Sato VA, Marques ID, Goldenstein PT, Carmo LP, Jorge LB, Titan SM, Barros RT, Woronik $\mathrm{V}$ : Lupus nephritis is more severe in children and adolescents than in older adults. Lupus 2012, 21:978-983.

22. Hui-Yuen JS, Imundo LF, Avitabile C, Kahn PJ, Eichenfield AH, Levy DM: Early versus later onset childhood-onset systemic lupus erythematosus: clinical features, treatment and outcome. Lupus 2011, 20:952-959.

23. Descloux E, Durieu I, Cochat P, Vital-Durand D, Ninet J, Fabien N, Cimaz R: Influence of age at disease onset in the outcome of paediatric systemic lupus erythematosus. Rheumatology (Oxford) 2009, 48:779-784.

24. Hoffman IE, Lauwerys BR, De Keyser F, Huizinga TW, Isenberg D, Cebecauer L, Dehoorne J, Joos R, Hendrickx G, Houssiau F, Elewaut D: Juvenile-onset systemic lupus erythematosus: different clinical and serological pattern than adult-onset systemic lupus erythematosus. Ann Rheum Dis 2009, 68:412-415.

25. Ramirez Gomez LA, Uribe Uribe O, Osio Uribe O, Grisales Romero H, Cardiel MH, Wojdyla D, Pons-Estel BA, Catoggio L, Soriano ER, Imamura PM, Manni JA, Grimaudo S, Sarano J, Maldonado-Cocco JA, Arriola MS, Gomez G, Garcia MA, Marcos Al, Marcos JC, Scherbarth HR, Marino PC, Motta EL, Drenkard C, Gamron S, Buliubasich S, Onetti CM, Caeiro F, Alvarellos A, Saurit V, Gentiletti $S$, et al: Childhood systemic lupus erythematosus in Latin America. The GLADEL experience in 230 children. Lupus 2008, 17:596-604.

26. Livingston B, Bonner A, Pope J: Differences in clinical manifestations between childhood-onset lupus and adult-onset lupus: a meta-analysis. Lupus 2011, 20:1345-1355.

27. Livingston B, Bonner A, Pope J: Differences in autoantibody profiles and disease activity and damage scores between childhood- and adult-onset systemic lupus erythematosus: a meta-analysis. Semin Arthritis Rheum 2012, 42:271-280

28. Benseler SM, Silverman ED: Neuropsychiatric involvement in pediatric systemic lupus erythematosus. Lupus 2007, 16:564-571.

29. Hanly JG, Urowitz MB, Sanchez-Guerrero J, Bae SC, Gordon C, Wallace DJ, Isenberg D, Alarcon GS, Clarke A, Bernatsky S, Merrill JT, Petri M, Dooley MA, Gladman D, Fortin PR, Steinsson K, Bruce I, Manzi S, Khamashta M, Zoma A, Aranow C, Ginzler E, Van Vollenhoven R, Font J, Sturfelt G, Nived O, RamseyGoldman R, Kalunian K, Douglas J, Thompson K, et al.: Neuropsychiatric events at the time of diagnosis of systemic lupus erythematosus: an international inception cohort study. Arthritis Rheum 2007, 56:265-273.

30. Williams TS, Aranow C, Ross GS, Barsdorf A, Imundo LF, Eichenfield AH, Kahn PJ, Diamond B, Levy DM: Neurocognitive impairment in childhood-onset systemic lupus erythematosus: measurement issues in diagnosis. Arthritis Care Res (Hoboken) 2011, 63:1178-1187.

31. Borowoy AM, Pope JE, Silverman E, Fortin PR, Pineau C, Smith CD, Arbillaga H, Gladman D, Urowitz M, Zummer M, Hudson M, Tucker L, Peschken C: Neuropsychiatric lupus: the prevalence and autoantibody associations depend on the definition: results from the 1000 faces of lupus cohort. Semin Arthritis Rheum 2012, 42:179-185.

32. Muscal E, Brey RL: Neurologic manifestations of systemic lupus erythematosus in children and adults. Neurol Clin 2010, 28:61-73.

33. Lilleby V: Bone status in juvenile systemic lupus erythematosus. Lupus 2007, 16:580-586

34. Yeap SS, Fauzi AR, Kong NC, Halim AG, Soehardy Z, Rahimah I, Chow SK, Goh EM: A comparison of calcium, calcitriol, and alendronate in corticosteroidtreated premenopausal patients with systemic lupus erythematosus. J Rheumatol 2008, 35:2344-2347.

35. Baker-LePain JC, Nakamura MC, Shepherd J, von Scheven E: Assessment of bone remodelling in childhood-onset systemic lupus erythematosus. Rheumatology (Oxford) 2011, 50:611-619.

36. Wright TB SJ, Leonard MB, Zemel BS, Burnham JM: Hypovitaminosis D is associated with greater body mass index and disease activity in pediatric systemic lupus erythematosus. J Pediatr 2009, 155:260-265.

37. Mok CC, Birmingham DJ, Ho LY, Hebert LA, Song H, Rovin BH: Vitamin D deficiency as marker for disease activity and damage in systemic lupus erythematosus: a comparison with anti-dsDNA and anti-C1q. Lupus 2011, 21:36-42.

38. Robinson AB, Thierry-Palmer M, Gibson KL, Rabinovich CE: Disease activity, proteinuria, and vitamin $D$ status in children with systemic lupus erythematosus and juvenile dermatomyositis. J Pediatr 2011, 160:297-302.

39. Schanberg LE, Sandborg C, Barnhart HX, Ardoin SP, Yow E, Evans GW, Mieszkalski KL, llowite NT, Eberhard A, Imundo LF, Kimura Y, von Scheven E, Silverman E, Bowyer SL, Punaro M, Singer NG, Sherry DD, McCurdy D, KleinGitelman M, Wallace C, Silver R, Wagner-Weiner L, Higgins GC, Brunner HI, Jung L, Soep JB, Reed AM, Provenzale J, Thompson SD: Use of atorvastatin in systemic lupus erythematosus in children and adolescents. Arthritis Rheum 2011, 64:285-296

40. Schanberg LE, Sandborg C, Barnhart HX, Ardoin SP, Yow E, Evans GW, Mieszkalski KL, llowite NT, Eberhard A, Levy DM, Kimura Y, von Scheven E, Silverman E, Bowyer SL, Punaro L, Singer NG, Sherry DD, McCurdy D, KleinGitelman M, Wallace C, Silver R, Wagner-Weiner L, Higgins GC, Brunner HI, Jung L, Soep JB, Reed A: Premature atherosclerosis in pediatric systemic lupus erythematosus: risk factors for increased carotid intima-media thickness in the atherosclerosis prevention in pediatric lupus erythematosus cohort. Arthritis Rheum 2009, 60:1496-1507.

41. Lionaki S, Kapitsinou PP, Iniotaki A, Kostakis A, Moutsopoulos HM, Boletis JN: Kidney transplantation in lupus patients: a case-control study from a single centre. Lupus 2008, 17:670-675.

42. Cochat P, Fargue S, Mestrallet G, Jungraithmayr T, Koch-Nogueira P, Ranchin B, Zimmerhackl LB: Disease recurrence in paediatric renal transplantation. Pediatr Nephrol 2009, 24:2097-2108.

43. Hiraki LT, Lu B, Alexander SR, Shaykevich T, Alarcon GS, Solomon DH, Winkelmayer WC, Costenbader KH: End-stage renal disease due to lupus nephritis among children in the US, 1995-2006. Arthritis Rheum 2011, 63:1988-1997.

44. Chambers SA, Allen E, Rahman A, Isenberg D: Damage and mortality in a group of British patients with systemic lupus erythematosus followed up for over 10 years. Rheumatology (Oxford) 2009, 48:673-675.

45. Huang JL, Yeh KW, Yao TC, Huang YL, Chung HT, Ou LS, Lee WI, Chen LC: Pediatric lupus in Asia. Lupus 2010, 19:1414-1418.

46. Vachvanichsanong P, Dissaneewate P, McNeil E: Twenty-two years' experience with childhood-onset SLE in a developing country: are outcomes similar to developed countries? Arch Dis Child 2011, 96:44-49.

47. Petri M, Purvey S, Fang H, Magder LS: Predictors of organ damage in systemic lupus erythematosus: the Hopkins Lupus Cohort. Arthritis Rheum 2012, 64:4021-4028.

48. Brunner HI, Silverman ED, To T, Bombardier C, Feldman BM: Risk factors for damage in childhood-onset systemic lupus erythematosus: cumulative disease activity and medication use predict disease damage. Arthritis Rheum 2002, 46:436-444.

49. Tucker LB, Uribe AG, Fernandez M, Vila LM, McGwin G, Apte M, Fessler B] Bastian HM, Reveille JD, Alarcon GS: Adolescent onset of lupus results in more aggressive disease and worse outcomes: results of a nested matched case-control study within LUMINA, a multiethnic US cohort (LUMINA LVIII). Lupus 2008, 17:314-322.

50. Hersh AO, Trupin L, Yazdany J, Panopalis P, Julian L, Katz P, Criswell LA, Yelin E: Childhood-onset disease as a predictor of mortality in an adult cohort of patients with systemic lupus erythematosus. Arthritis Care Res (Hoboken) 2010, 62:1152-1159.

51. Mina R K-GM, Nelson S, Eberhard BA, Higgins G, Singer NG, Onel K, Tucker L, O'Neil KM, Punaro M, Levy DM, Haines K, Martini A, Ruperto N, Lovell D, Brunner $\mathrm{HI}$ : Validation of the systemic lupus erythematosus responder index for use in juvenile-onset systemic lupus erythematosus. Ann Rheum Dis 2013, in press. [Epub ahead of print]

52. Mina R, Klein-Gitelman MS, Ravelli A, Beresford MW, Avcin T, Espada G, Eberhard BA, Schanberg LE, O'Neil KM, Silva CA, Higgins GC, Onel K, Singer $N G$, von Scheven E, Imundo LF, Nelson S, Giannini EH, Brunner HI: Inactive disease and remission in childhood-onset systemic lupus erythematosus. Arthritis Care Res (Hoboken) 2012, 64:683-693.

53. Ruperto N, Hanrahan LM, Alarcon GS, Belmont HM, Brey RL, Brunetta P, Buyon JP, Costner MI, Cronin ME, Dooley MA, Filocamo G, Fiorentino D, Fortin PR, Franks AG, Jr., Gilkeson G, Ginzler E, Gordon C, Grossman J, Hahn B, Isenberg DA, Kalunian KC, Petri M, Sammaritano L, Sanchez-Guerrero J, Sontheimer RD, Strand V, Urowitz M, von Feldt JM, Werth VP, Merrill JT: International consensus for a definition of disease flare in lupus. Lupus 2010, 20:453-462

54. Brunner HI, Klein-Gitelman MS, Higgins GC, Lapidus SK, Levy DM, Eberhard A, Singer N, Olson JC, Onel K, Punaro M, Schanberg L, von Scheven E, Ying J, Giannini EH: Toward the development of criteria for global flares in juvenile systemic lupus erythematosus. Arthritis Care Res (Hoboken) 2010, 62:811-820. 
55. Mina R, von Scheven E, Ardoin SP, Eberhard BA, Punaro M, llowite N, Hsu J, Klein-Gitelman M, Moorthy LN, Muscal E, Radhakrishna SM, Wagner-Weiner L, Adams M, Blier P, Buckley L, Chalom E, Chedeville G, Eichenfield A, Fish N, Henrickson M, Hersh AO, Hollister R, Jones O, Jung L, Levy D, Lopez-Benitez J, McCurdy D, Miettunen PM, Quintero-del Rio Al, Rothman D, et al:: Consensus treatment plans for induction therapy of newly diagnosed proliferative lupus nephritis in juvenile systemic lupus erythematosus. Arthritis Care Res (Hoboken) 2011, 64:375-383.

56. Renal Disease Subcommittee of the American College of Rheumatology Ad Hoc Committee on Systemic Lupus Erythematosus Response Criteria:The American College of Rheumatology response criteria for proliferative and membranous renal disease in systemic lupus erythematosus clinical trials. Arthritis Rheum 2006, 54:421-432.

57. Watson L, Midgley A, Pilkington C, Tullus K, Marks S, Holt R, Jones C, Beresford M: Urinary monocyte chemoattractant protein 1 and alpha 1 acid glycoprotein as biomarkers of renal disease activity in juvenile-onset systemic lupus erythematosus. Lupus 2011, 21:496-501.

58. RRubinstein T, Pitashny M, Levine B, Schwartz N, Schwartzman J, Weinstein E, Pego-Reigosa JM, Lu TY, Isenberg D, Rahman A, Putterman C: Urinary neutrophil gelatinase-associated lipocalin as a novel biomarker for disease activity in lupus nephritis. Rheumatology (Oxford) 2010, 49:960-971.

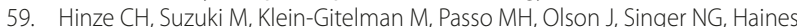
KA, Onel K, O'Neil K, Silverman ED, Tucker L, Ying J, Devarajan P, Brunner HI: Neutrophil gelatinase-associated lipocalin is a predictor of the course of global and renal childhood-onset systemic lupus erythematosus disease activity. Arthritis Rheum 2009, 60:2772-2781.

60. Kao AH, Navratil JS, Ruffing MJ, Liu CC, Hawkins D, McKinnon KM, Danchenko N, Ahearn JM, Manzi S: Erythrocyte C3d and C4d for monitoring disease activity in systemic lupus erythematosus. Arthritis Rheum 2010, 62:837-844

61. Reyes-Thomas J, Blanco I, Putterman C: Urinary biomarkers in lupus nephritis. Clin Rev Allergy Immunol 2011, 40:138-150.

62. Hollander MC, Sage JM, Greenler AJ, Pendl J, Avcin T, Espada G, Beresford MW, Henrickson M, Lee TL, Punaro M, Huggins J, Stevens AM, Klein-Gitelman MS, Brunner HI: International consensus for provisions of quality-driven care in childhood-onset systemic lupus erythematosus. Arthritis Care Res (Hoboken) 2013, in press doi: 10.1002/acr.21998.

63. Yazdany J, Panopalis P, Gillis JZ, Schmajuk G, MacLean CH, Wofsy D, Yelin E: A quality indicator set for systemic lupus erythematosus. Arthritis Rheum 2009, 61:370-377.

64. Mosca M, Tani C, Aringer M, Bombardieri S, Boumpas D, Brey R, Cervera R, Doria A, Jayne D, Khamashta MA, Kuhn A, Gordon C, Petri M, Rekvig OP, Schneider M, Sherer Y, Shoenfeld Y, Smolen JS, Talarico R, Tincani A, van Vollenhoven RF, Ward MM, Werth VP, Carmona L: European League Against Rheumatism recommendations for monitoring patients with systemic lupus erythematosus in clinical practice and in observational studies. Ann Rheum Dis 2010, 69:1269-1274.

65. Furie R, Petri M, Zamani O, Cervera R, Wallace DJ, Tegzova D, SanchezGuerrero J, Schwarting A, Merrill JT, Chatham WW, StohI W, Ginzler EM, Hough DR, Zhong ZJ, Freimuth W, van Vollenhoven RF: A phase III, randomized, placebo-controlled study of belimumab, a monoclonal antibody that inhibits B lymphocyte stimulator, in patients with systemic lupus erythematosus. Arthritis Rheum 2011, 63:3918-3930.

66. Wallace DJ, StohI W, Furie RA, Lisse JR, McKay JD, Merrill JT, Petri MA, Ginzler EM, Chatham WW, McCune WJ, Fernandez V, Chevrier MR, Zhong ZJ, Freimuth WW: A phase II, randomized, double-blind, placebo-controlled, dose-ranging study of belimumab in patients with active systemic lupus erythematosus. Arthritis Rheum 2009, 61:1168-1178.

67. Kumar S, Benseler SM, Kirby-Allen M, Silverman ED: B-cell depletion for autoimmune thrombocytopenia and autoimmune hemolytic anemia in pediatric systemic lupus erythematosus. Pediatrics 2009, 123:e159-e163.
68. Terrier B, Amoura Z, Ravaud P, Hachulla E, Jouenne R, Combe B, Bonnet C, Cacoub P, Cantagrel A, de Bandt M, Fain O, Fautrel B, Gaudin P, Godeau B, Harle JR, Hot A, Kahn JE, Lambotte O, Larroche C, Leone J, Meyer O, PallotPrades B, Pertuiset E, Quartier P, Schaerverbeke T, Sibilia J, Somogyi A, Soubrier M, Vignon E, Bader-Meunier B, et al:: Safety and efficacy of rituximab in systemic lupus erythematosus: results from 136 patients from the French Autolmmunity and Rituximab registry. Arthritis Rheum 2010, 62:2458-2466.

69. Merrill JT, Neuwelt CM, Wallace DJ, Shanahan JC, Latinis KM, Oates JC, Utset TO, Gordon C, Isenberg DA, Hsieh HJ, Zhang D, Brunetta PG: Efficacy and safety of rituximab in moderately-to-severely active systemic lupus erythematosus: the randomized, double-blind, phase II/III systemic lupus erythematosus evaluation of rituximab trial. Arthritis Rheum 2010, 62:222-233.

70. Hahn BH, McMahon MA, Wilkinson A, Wallace WD, Daikh DI, Fitzgerald JD, Karpouzas GA, Merrill JT, Wallace DJ, Yazdany J, Ramsey-Goldman R, Singh K, Khalighi M, Choi SI, Gogia M, Kafaja S, Kamgar M, Lau C, Martin WJ, Parikh S, Peng J, Rastogi A, Chen W, Grossman JM: American College of Rheumatology guidelines for screening, treatment, and management of lupus nephritis. Arthritis Care Res (Hoboken) 2012, 64:797-808.

71. Bertsias GK, Tektonidou M, Amoura Z, Aringer M, Bajema I, Berden JH, Boletis J, Cervera R, Dorner T, Doria A, Ferrario F, Floege J, Houssiau FA, loannidis JP, Isenberg DA, Kallenberg CG, Lightstone L, Marks SD, Martini A, Moroni G, Neumann I, Praga M, Schneider M, Starra A, Tesar V, Vasconcelos C, van Vollenhoven RF, Zakharova H, Haubitz M, Gordon C, et al:: Joint European League Against Rheumatism and European Renal Association-European Dialysis and Transplant Association (EULAR/ERA-EDTA) recommendations for the management of adult and paediatric lupus nephritis. Ann Rheum Dis 2012, 71:1771-1782

72. Ginzler EM, Dooley MA, Aranow C, Kim MY, Buyon J, Merrill JT, Petri M, Gilkeson GS, Wallace DJ, Weisman MH, Appel GB: Mycophenolate mofetil or intravenous cyclophosphamide for lupus nephritis. N Engl J Med 2005, 353:2219-2228.

73. Sundel R, Solomons N, Lisk L: Efficacy of mycophenolate mofetil in adolescent patients with lupus nephritis: evidence from a two-phase, prospective randomized trial. Lupus 2012, 21:1433-1443.

74. Dooley MA, Jayne D, Ginzler EM, Isenberg D, Olsen NJ, Wofsy D, Eitner F, Appel GB, Contreras G, Lisk L, Solomons N: Mycophenolate versus azathioprine as maintenance therapy for lupus nephritis. N Engl J Med 2011, 365:1886-1895.

75. Henderson L, Masson P, Craig JC, Flanc RS, Roberts MA, Strippoli GF, Webster AC: Treatment for lupus nephritis. Cochrane Database Syst Rev 2012, 12:CD002922.

76. Slawsky KA, Fernandes AW, Fusfeld L, Manzi S, Goss TF: A structured literature review of the direct costs of adult systemic lupus erythematosus in the US. Arthritis Care Res (Hoboken) 2011, 63:1224-1232.

77. Tanzer M, Tran C, Messer KL, Kroeker A, Herreshoff E, Wickman L, Harkness C, Song $\mathrm{P}$, Gipson DS: Inpatient healthcare utilization by children and adolescents with systemic lupus erythematosus and kidney involvement. Arthritis Care Res (Hoboken) 2013, 65:382-390.

78. Zhu TY, Tam LS, Li EK: Cost-of-illness studies in systemic lupus erythematosus: a systematic review. Arthritis Care Res (Hoboken) 2011, 63:751-760.

doi:10.1186/ar4256

Cite this article as: Mina R, Brunner HI: Update on differences between childhood-onset and adult-onset systemic lupus erythematosus. Arthritis Research \& Therapy 2013, 15:218. 